\title{
Efficacy of abrocitinib for atopic dermatitis: a meta-analysis of randomized controlled trials
}

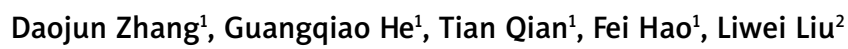 \\ ${ }^{1}$ Department of Skin Plastic Surgery and Beauty, The Third Affiliated Hospital of Chongqing Medical University, Chongqing, China \\ ${ }^{2}$ Chongqing Shapingba District People's Hospital, Chongqing, China \\ Adv Dermatol Allergol 2022; XXXIX (5): 872-876 \\ DOI: https://doi.org/10.5114/ada.2021.110269
}

\begin{abstract}
Introduction: The efficacy of abrocitinib for atopic dermatitis remains controversial.

Aim: We conducted a systematic review and meta-analysis to explore the influence of abrocitinib versus placebo on the treatment of atopic dermatitis.

Material and methods: We searched PubMed, Embase, Web of Science, EBSCO, and Cochrane Library databases up to June 2021 for randomized controlled trials (RCTs) assessing the effect of abrocitinib versus placebo for patients with atopic dermatitis. This meta-analysis was performed using a random-effect model.

Results: Four RCTs involving 932 patients were included in the meta-analysis. Overall, compared with the control group for atopic dermatitis, abrocitinib has a remarkably positive impact on IGA response $(\mathrm{OR}=6.60 ; 95 \% \mathrm{Cl}$ : 4.41-9.87; $p<0.00001)$, EASI-75 (OR = 9.19; 95\% Cl: 6.20-13.61; $p<0.00001)$, EASI-90 (OR = 10.50; 95\% Cl: 5.54-19.93; $p<0.0001)$, NRS response $(\mathrm{OR}=6.99 ; 95 \% \mathrm{Cl}: 4.43-11.01 ; p<0.00001)$ and adverse events $(\mathrm{OR}=1.76 ; 95 \% \mathrm{Cl}: 1.23-2.52 ; p=0.002)$, but showed no obvious influence on serious adverse events $(\mathrm{OR}=0.53 ; 95 \% \mathrm{Cl}: 0.20-1.44 ; p=0.22)$.

Conclusions: Abrocitinib exerts a favorable effect on the treatment of atopic dermatitis.
\end{abstract}

Key words: abrocitinib, atopic dermatitis, randomized controlled trials, meta-analysis.

\section{Introduction}

Atopic dermatitis, a chronic and relapsing inflammatory skin condition, results in intense pruritus [1-5]. Its complex pathophysiology involves the interplay of impaired skin barrier function, immune dysregulation, genetic susceptibility, and environmental factors [6-8]. Atopic dermatitis is estimated to affect up to $20 \%$ of children and adolescents and up to $10 \%$ of adults. These patients have considerable impairment in quality of life, sleep, depression, anxiety, and work absenteeism [9-11].

Management of atopic dermatitis needs systemic therapy, and there is still a lack of effective treatment for some patients with atopic dermatitis [12-14]. Abrocitinib (called PF04965842), an oral Janus kinase (JAK) 1 selective inhibitor, reveals some potential for the treatment of atopic dermatitis. Oral abrocitinib was documented to be effective and well tolerated in a dose-ranging phase $2 \mathrm{~b}$ study in adults with moderatetosevere atopic dermatitis with regard to the improvement in Investigator Global Assessment (IGA) response and Eczema Area and Severity Index (EASI) score [15].
However, the efficacy of abrocitinib versus placebo for atopic dermatitis has not been well established. Recently, several studies on the topic have been published [16-18].

\section{Aim}

With accumulating evidence, we therefore performed a systematic review and meta-analysis of RCTs to explore the efficacy of abrocitinib for patients with atopic dermatitis.

\section{Material and methods}

Ethical approval and patient consent are not required because this is a systematic review and meta-analysis of previously published studies. The systematic review and meta-analysis was conducted and reported in adherence to PRISMA (Preferred Reporting Items for Systematic Reviews and Meta-Analyses) [19].

Address correspondence: Liwei Liu, Chongqing Shapingba District People’s Hospital, 44 Xiaolongkan New Street, Shapingba District, Chongqing, China, phone/fax: +8602389342584, e-mail: Liuliwei1413@163.com Received: 12.07.2021, accepted: 21.07.2021. 


\section{Search strategy and study selection}

Two investigators independently searched the following databases (inception to June 2021): PubMed, Embase, Web of Science, EBSCO, and Cochrane Library databases. The electronic search strategy was conducted using the following keywords: "abrocitinib" AND "atopic dermatitis". We also checked the reference lists of the screened full-text studies to identify other potentially eligible trials.

The inclusive selection criteria were as follows: (i) population: patients with atopic dermatitis; (ii) intervention: abrocitinib at the dose of $200 \mathrm{mg}$ once daily; (iii) comparison: placebo; (iv) study design: RCT.

\section{Data extraction and outcome measures}

We extracted the following information: author, number of patients, age, female, duration of atopic dermatitis, Eczema Area and Severity Index (EASI) score and detailed methods in each group, etc. Data were extracted independently by two investigators, and discrepancies were resolved by consensus. We also contacted the corresponding author to obtain the data when necessary.

The primary outcomes were IGA response and EASI75. Secondary outcomes included EASI-90, NRS response, adverse events and serious adverse events.

\section{Quality assessment in individual studies}

Methodological quality of the included studies was independently evaluated using the modified Jadad scale [20]. There are 3 items for the Jadad scale: randomization (0-2 points), blinding ( $0-2$ points), dropouts and withdrawals ( $0-1$ points). The score of the Jadad scale varies from 0 to 5 points. An article with a Jadad score $\leq 2$ is considered to be of low quality. If the Jadad score $\geq 3$, the study is considered to be of high quality [21].

\section{Statistical analysis}

We estimated the odds ratio (OR) with $95 \% \mathrm{Cls}$ for all dichotomous outcomes. A random-effects model was used regardless of heterogeneity. Heterogeneity is reported using the $R$ statistic, and $R>50 \%$ indicates significant heterogeneity [22]. Whenever significant heterogeneity was present, we searched for potential sources of heterogeneity via omitting one study in turn for the meta-analysis or performing subgroup analysis. All statistical analyses were performed using Review Manager Version 5.3 (The Cochrane Collaboration, Software Update, Oxford, UK).

\section{Results}

\section{Literature search, study characteristics and quality} assessment

A detailed flowchart of the search and selection results is shown in Figure 1. One hundred and fifty-two potentially relevant articles were identified initially. Finally, four RCTs that met our inclusion criteria were included in the meta-analysis [15-18].

The baseline characteristics of the four eligible RCTs in the meta-analysis are summarized in Table 1 . The six studies were published between 2019 and 2021, and total sample size is 932. The intervention treatments are $200 \mathrm{mg}$ of abrocitinib once daily versus placebo for 12 weeks.

Among the four studies included here, four studies report the Investigator's Global Assessment (IGA) response and EASI-75 [15-18], three studies report the EASI-90 and Numerical Rating Scale (NRS) response $[15,17,18]$, three studies report adverse events and serious adverse events [16-18]. Jadad scores of the four included studies vary from 4 to 5 , and all four studies are considered to be high-quality ones according to quality assessment.

\section{Primary outcomes: IGA response and EASI-75}

These outcome data were analyzed with the randomeffects model, and compared to the control group, for atopic dermatitis, abrocitinib results in a significantly higher IGA response $(\mathrm{OR}=6.60 ; 95 \% \mathrm{Cl}: 4.41-9.87 ; p<0.00001)$ with no heterogeneity among the studies $\left(R^{2}=0 \%\right.$, heterogeneity $p=0.54)$ (Figure 2$)$ and EASI-75 (OR $=9.19 ; 95 \% \mathrm{Cl}$ : 6.20-13.61; $p<0.00001)$ with low heterogeneity among the studies $\left({ }^{2}=19 \%\right.$, heterogeneity $\left.p=0.29\right)$ (Figure 3$)$.

\section{Sensitivity analysis}

No significant heterogeneity was observed among the included studies, and thus we did not perform sensitivity analysis via omitting one study in turn.

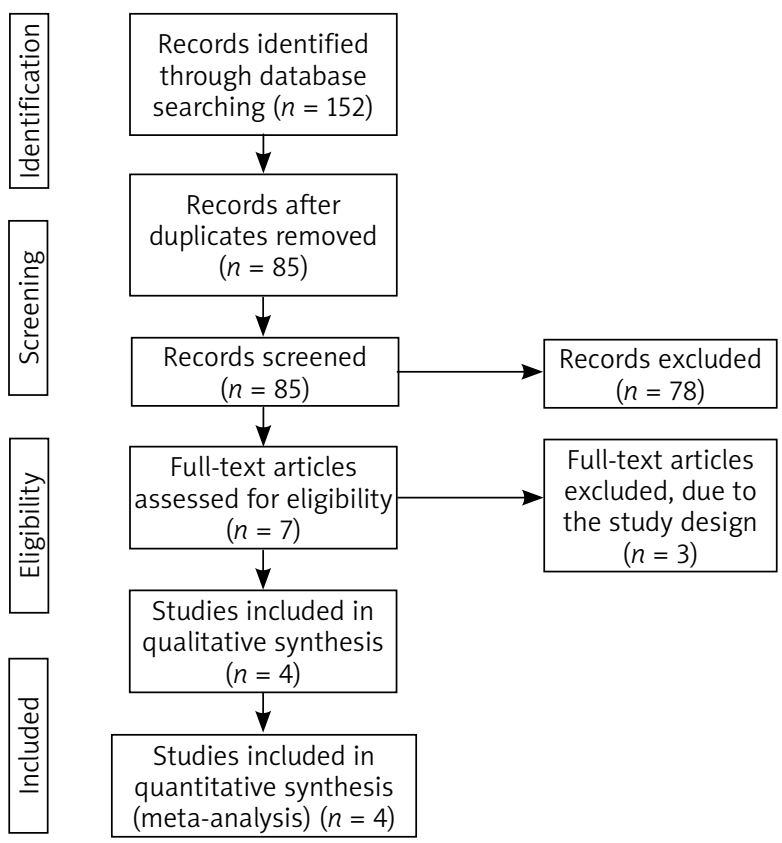

Figure 1. Flow diagram of study search and selection process 
Table 1. Characteristics of included studies

\begin{tabular}{|c|c|c|c|c|c|c|c|c|c|c|c|c|c|}
\hline \multirow[b]{2}{*}{$\frac{\grave{2}}{\stackrel{ }{+}}$} & \multicolumn{6}{|c|}{ Abrocitinib group } & \multicolumn{6}{|c|}{ Control group } & \multirow{2}{*}{$\begin{array}{l}\text { Jadad } \\
\text { scores }\end{array}$} \\
\hline & Number & $\begin{array}{c}\text { Age } \\
\text { [years] }\end{array}$ & $\begin{array}{c}\text { Female } \\
(n)\end{array}$ & $\begin{array}{c}\text { Duration } \\
\text { of atopic } \\
\text { dermatitis } \\
\text { [years] }\end{array}$ & $\begin{array}{l}\text { EASI } \\
\text { score }\end{array}$ & Methods & Number & $\begin{array}{c}\text { Age } \\
\text { [years] }\end{array}$ & $\begin{array}{c}\text { Female } \\
(n)\end{array}$ & $\begin{array}{c}\text { Duration } \\
\text { of atopic } \\
\text { dermatitis } \\
\text { [years] }\end{array}$ & $\begin{array}{l}\text { EASI } \\
\text { score }\end{array}$ & Methods & \\
\hline 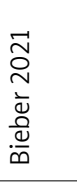 & 226 & $\begin{array}{r}38.8 \\
\pm 14.5\end{array}$ & 122 & $23.4 \pm 15.6$ & $\begin{array}{c}32.1 \\
\pm 13.1\end{array}$ & $\begin{array}{c}200 \text { mg of } \\
\text { abrocitinib } \\
\text { orally once } \\
\text { daily for } \\
12 \text { weeks }\end{array}$ & 131 & $\begin{array}{c}37.4 \\
\pm 15.2\end{array}$ & 54 & $21.4 \pm 14.4$ & $\begin{array}{c}31.0 \\
\pm 12.6\end{array}$ & Placebo & 4 \\
\hline 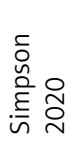 & 154 & $\begin{array}{c}33.0 \\
\pm 17.4\end{array}$ & 73 & $22.7 \pm 14.5$ & $\begin{array}{c}30.6 \\
\pm 14.1\end{array}$ & $\begin{array}{c}200 \text { mg of } \\
\text { abrocitinib } \\
\text { once daily for } \\
12 \text { weeks }\end{array}$ & 77 & $\begin{array}{c}31.5 \\
\pm 14.4\end{array}$ & 28 & $22.5 \pm 14.4$ & $\begin{array}{r}28.7 \\
\pm 12.5\end{array}$ & Placebo & 4 \\
\hline 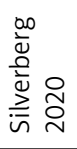 & 155 & $\begin{array}{c}33.5 \\
\pm 14.7\end{array}$ & 67 & $20.5 \pm 14.8$ & $\begin{array}{c}29.0 \\
\pm 12.4\end{array}$ & $\begin{array}{l}200 \text { mg of } \\
\text { abrocitinib } \\
\text { once daily for } \\
12 \text { weeks }\end{array}$ & 78 & $\begin{array}{c}33.4 \\
\pm 13.8\end{array}$ & 31 & $21.7 \pm 14.3$ & $\begin{array}{c}28.0 \\
\pm 10.2\end{array}$ & Placebo & 5 \\
\hline $\begin{array}{l}\frac{E}{T} \\
\frac{\sigma}{L} \\
\frac{1}{0} \\
\frac{0}{0} \\
0 \\
0\end{array}$ & 55 & $\begin{array}{c}38.7 \\
\pm 17.6\end{array}$ & 27 & $\begin{array}{c}19.6 \text { (1.9- } \\
\text { 68.8), median } \\
\text { (range) }\end{array}$ & $\begin{array}{r}24.6 \\
\pm 13.5\end{array}$ & $\begin{array}{c}200 \text { mg of } \\
\text { abrocitinib } \\
\text { once daily for } \\
12 \text { weeks }\end{array}$ & 56 & $\begin{array}{r}42.6 \\
\pm 15.1\end{array}$ & 35 & $\begin{array}{c}25.6(1.1- \\
67.1), \text { median } \\
\text { (range) }\end{array}$ & $\begin{array}{c}25.4 \\
\pm 12.9\end{array}$ & Placebo & 5 \\
\hline
\end{tabular}

\section{Secondary outcomes}

In comparison with the control group for atopic dermatitis, abrocitinib is associated with substantially improved EASI-90 (OR = 10.50; 95\% Cl: 5.54-19.93; $p<0.0001$; Figure 4), NRS response $(\mathrm{OR}=6.99 ; 95 \% \mathrm{Cl}$ : 4.43-11.01; $p<0.00001$; Figure 5) and adverse events (OR $=1.76 ; 95 \% \mathrm{Cl}: 1.23-2.52 ; p=0.002$; Figure 6$)$, but no obvious impact on serious adverse events was revealed $(\mathrm{OR}=0.53 ; 95 \% \mathrm{Cl}: 0.20-1.44 ; p=0.22$; Figure 7$)$.

\section{Discussion}

Systemic corticosteroids may have higher efficacy than topical treatments in patients with moderate to severe atopic dermatitis, but is limited by short-term and long-term side effects, and long-term use is not recommended [23]. Other treatment options include immunosuppressive drugs (e.g. ciclosporin, methotrexate, azathioprine, and mycophenolate mofetil), but they are not approved due to adverse events and poor tolerability [23].

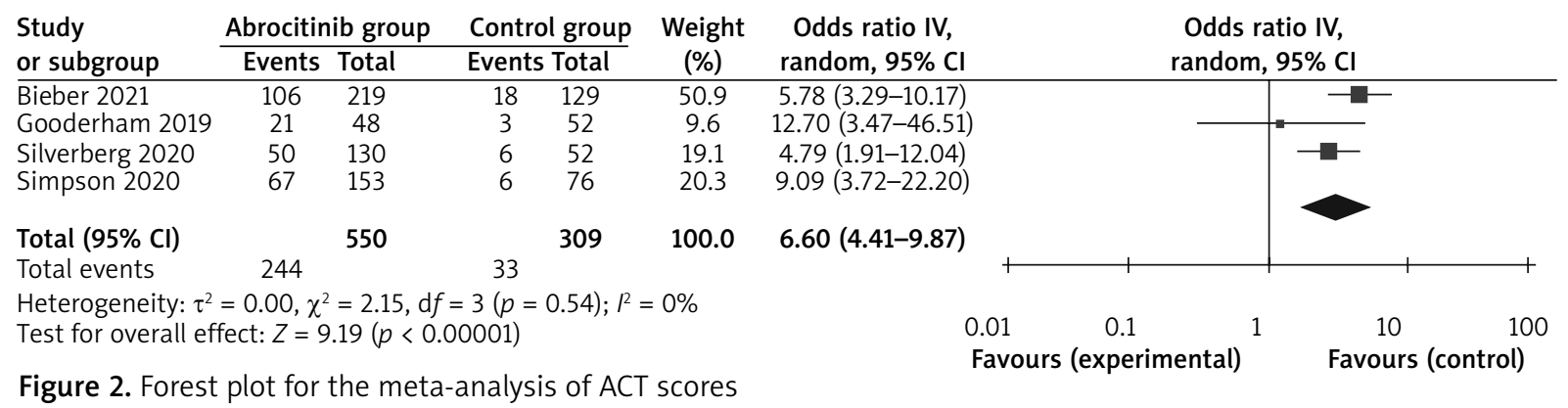

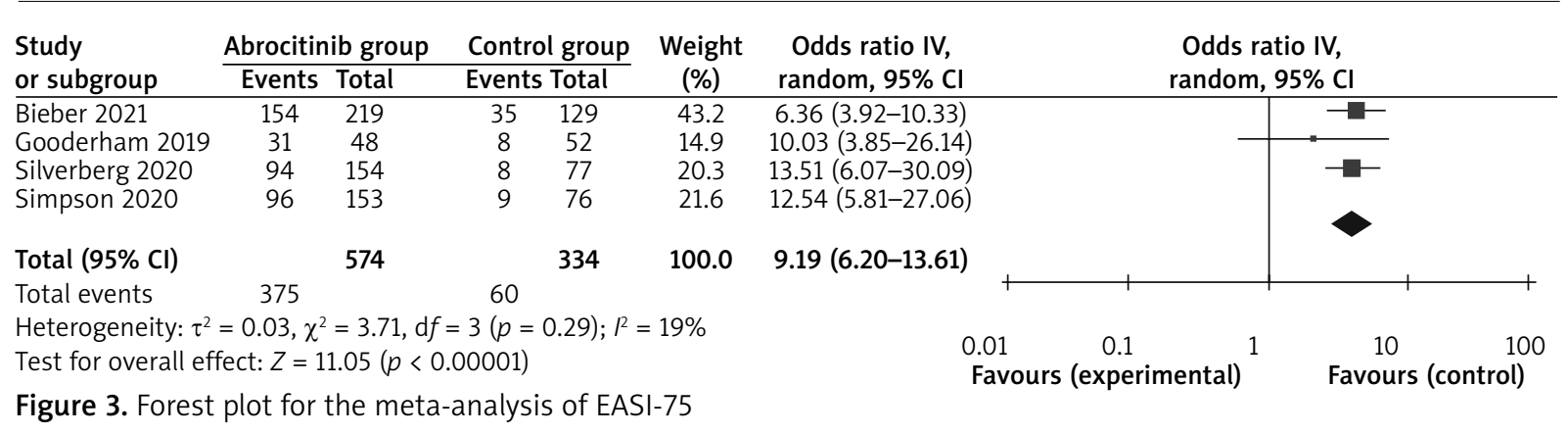




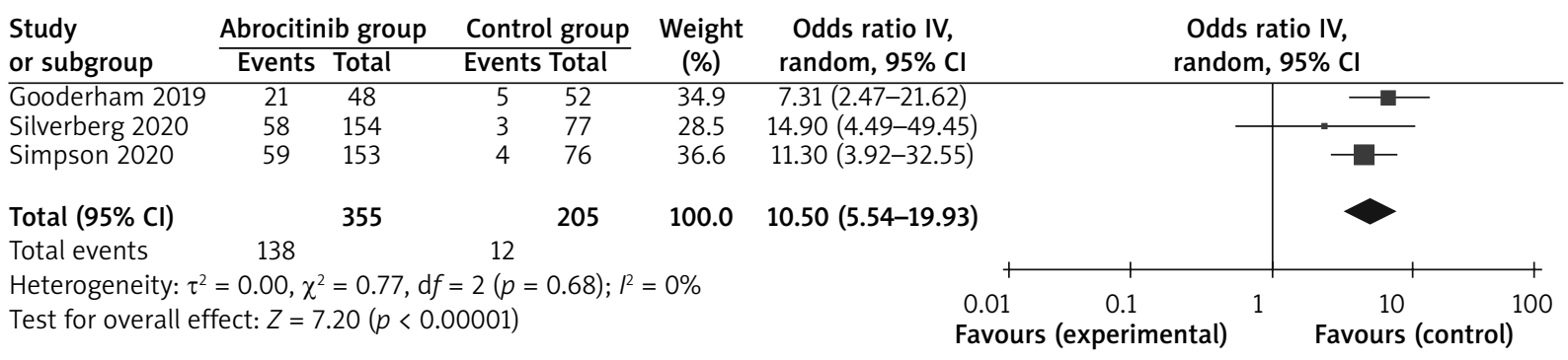

Figure 4. Forest plot for the meta-analysis of EASI-90

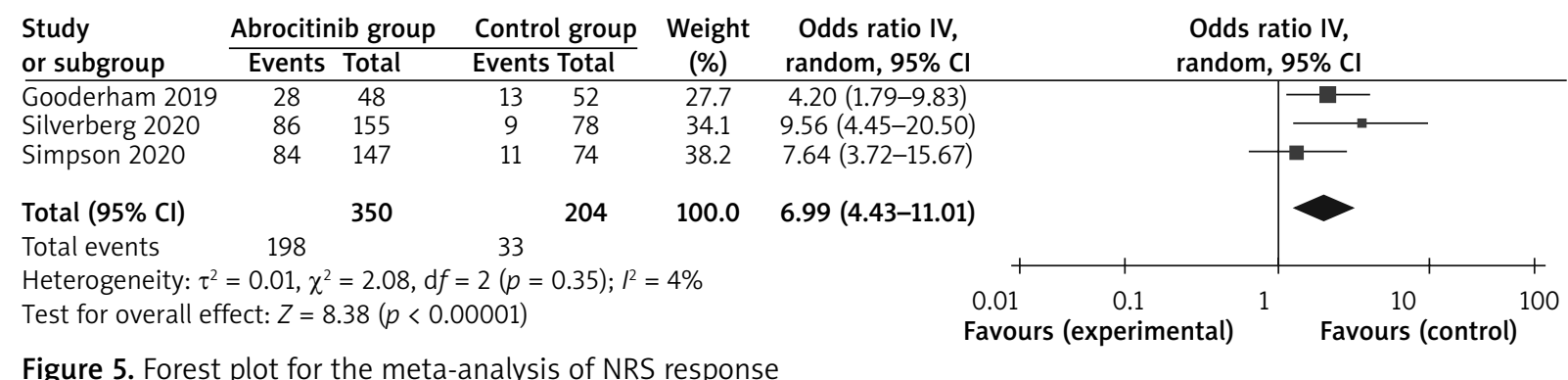

Figure 5. Forest plot for the meta-analysis of NRS response

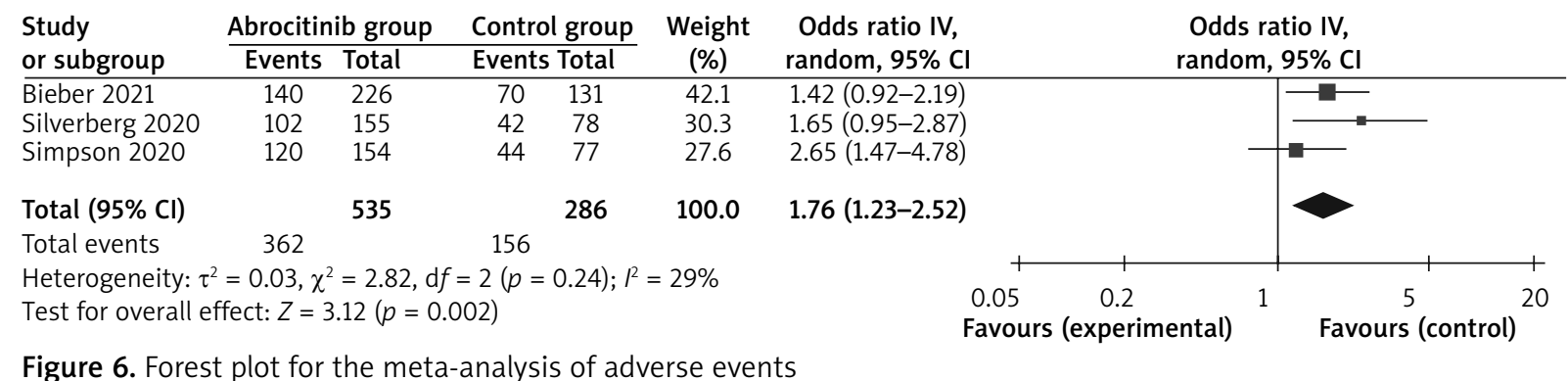

Figure 6. Forest plot for the meta-analysis of adverse events

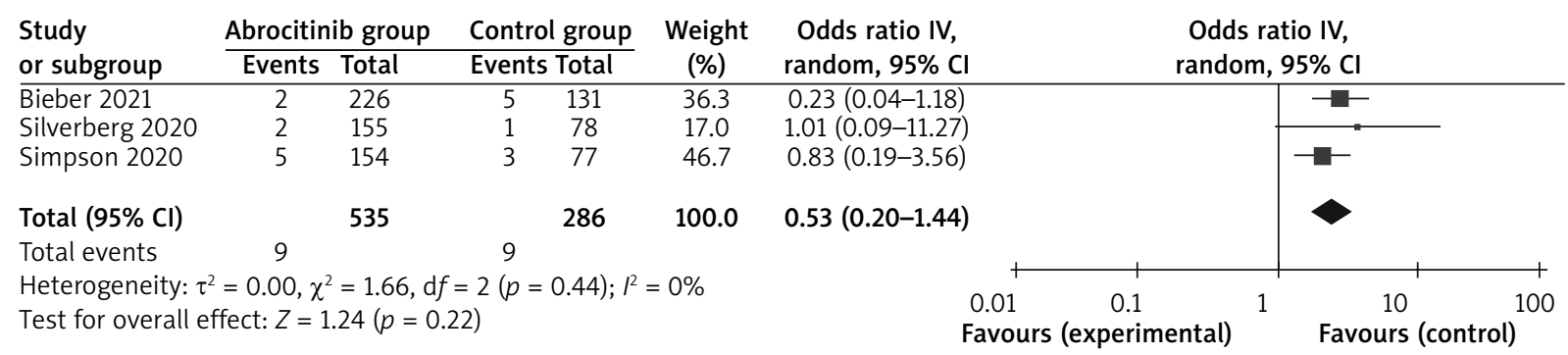

Figure 7. Forest plot for the meta-analysis of serious adverse events

One phase $2 \mathrm{~b}$ trial and two phase 3 placebo-controlled trials demonstrated that 12 weeks of monotherapy with abrocitinib resulted in better outcomes for atopic dermatitis than placebo $[15,17,18]$.

Our meta-analysis included four RCTs and 932 patients with atopic dermatitis. The results showed that abrocitinib at the dose of $200 \mathrm{mg}$ once daily promoted a significant improvement in IGA response, EASI-75, EASI90 and NRS response compared to placebo. Abrocitinib, a small-molecule JAK1 inhibitor, can be administered orally once daily, and promotes the treatment efficacy through inhibiting signaling of interleukin-4, interleukin-13, and other cytokines involved in the pathogenesis of atopic dermatitis [24]. Abrocitinib was reported to be less likely to stimulate an immunogenic response than biologic treatment $[25,26]$.

Considering the adverse events of abrocitinib at the dose of $200 \mathrm{mg}$ once daily, our results showed obviously more total adverse events than placebo, but these adverse events were generally mild and acceptable. These increased adverse events mainly include nausea and headache [17]. However, the incidence of serious adverse 
events was not increased by abrocitinib treatment. JAK inhibition can potentially increase the risk of infections due to the involvement of JAKs in signaling pathways that regulate host defense and the immune response [27]. However, one RCT revealed that the incidence of serious infections and herpes virus infections was low. No cases of malignancy were seen [17].

This meta-analysis has several potential limitations. Firstly, our analysis is based on only four RCTs, and more RCTs with a large sample size should be conducted to explore this issue. Secondly, considering the sensitivity analysis, although there is no significant heterogeneity, different severity levels of atopic dermatitis may produce some bias. Thirdly, no obvious increase in serious adverse events was seen after the 12-week treatment with abrocitinib, and longer follow-up should be conducted to confirm its safety.

\section{Conclusions}

Abrocitinib is effective and safe to treat atopic dermatitis.

\section{Conflict of interest}

The authors declare no conflict of interest.

\section{References}

1. Eichenfield LF, Tom WL, Chamlin SL, et al. Guidelines of care for the management of atopic dermatitis: section 1. Diagnosis and assessment of atopic dermatitis. J Am Acad Dermatol 2014; 70: 338-51.

2. Torres T, Ferreira EO, Gonçalo M, et al. Update on atopic dermatitis. Acta Med Portug 2019; 32: 606-13.

3. Vakharia PP, Silverberg JI. Adult-onset atopic dermatitis: characteristics and management. Am J Clin Dermatol 2019; 20: 771-9.

4. Mayba JN, Gooderham MJ. Review of atopic dermatitis and topical therapies. J Cutaneous Med Surg 2017; 21: 227-36.

5. Kido-Nakahara M, Furue M, Ulzii D, Nakahara T. Itch in atopic dermatitis. Immunol Allergy Clin N Am 2017; 37: 113-22.

6. Werfel T, Allam JP, Biedermann T, et al. Cellular and molecular immunologic mechanisms in patients with atopic dermatitis. J Allergy Clin Immunol 2016; 138: 336-49.

7. Boothe WD, Tarbox JA, Tarbox MB. Atopic dermatitis: pathophysiology. Adv Exp Med Biol 2017; 1027: 21-37.

8. Kim J, Kim BE, Leung DYM. Pathophysiology of atopic dermatitis: clinical implications. Allergy Asthma Proc 2019; 40: 84-92.

9. Rønnstad ATM, Halling-Overgaard AS, Hamann CR, et al. Association of atopic dermatitis with depression, anxiety, and suicidal ideation in children and adults: a systematic review and meta-analysis. J Am Acad Dermatol 2018; 79: 448-56.

10. Silverberg JI, Hanifin JM. Adult eczema prevalence and associations with asthma and other health and demographic factors: a US population-based study. J Allergy Clin Immunol 2013; 132: 1132-8.

11. Carroll CL, Balkrishnan R, Feldman SR, et al. The burden of atopic dermatitis: impact on the patient, family, and society. Pediatr Dermatol 2005; 22: 192-9.
12. Cabanillas B, Brehler AC, Novak N. Atopic dermatitis phenotypes and the need for personalized medicine. Curr Opin Allergy Clin Immunol 2017; 17: 309-15.

13. Sidbury R, Kodama S. Atopic dermatitis guidelines: diagnosis, systemic therapy, and adjunctive care. Clin Dermatol 2018; 36: 648-52.

14. Puar N, Chovatiya R, Paller AS. New treatments in atopic dermatitis. Ann Allergy Asthma Immunol 2021; 126: 21-31.

15. Gooderham MJ, Forman SB, Bissonnette R, et al. Efficacy and safety of oral janus kinase 1 inhibitor abrocitinib for patients with atopic dermatitis: a phase 2 randomized clinical trial. JAMA Dermatol 2019; 155: 1371-9.

16. Bieber T, Simpson EL, Silverberg Jl, et al. Abrocitinib versus placebo or dupilumab for atopic dermatitis. N Engl I Med 2021; 384: 1101-12.

17. Simpson EL, Sinclair R, Forman S, et al. Efficacy and safety of abrocitinib in adults and adolescents with moderateto-severe atopic dermatitis (JADE MONO-1): a multicentre, double-blind, randomised, placebo-controlled, phase 3 trial. Lancet 2020; 396: 255-66.

18. Silverberg JI, Simpson EL, Thyssen JP, et al. Efficacy and safety of abrocitinib in patients with moderate-to-severe atopic dermatitis: a randomized clinical trial. JAMA Dermatol 2020; 156: 863-73.

19. Moher D, Liberati A, Tetzlaff J, et al. Preferred reporting items for systematic reviews and meta-analyses: the PRISMA statement. J Clin Epidemiol 2009; 62: 1006-12.

20. Jadad AR, Moore RA, Carroll D, et al. Assessing the quality of reports of randomized clinical trials: is blinding necessary? Control Clin Trials 1996; 17: 1-12.

21. Kjaergard LL, Villumsen J, Gluud C. Reported methodologic quality and discrepancies between large and small randomized trials in meta-analyses. Ann Intern Med 2001; 135: 982-9.

22. Higgins JP, Thompson SG. Quantifying heterogeneity in a meta-analysis. Statistics Med 2002; 21: 1539-58.

23. Wollenberg A, Barbarot S, Bieber T, et al. Consensus-based European guidelines for treatment of atopic eczema (atopic dermatitis) in adults and children: part II. J Eur Acad Dermatol Venereol 2018; 32: 850-78.

24. Pavel AB, Zhou L, Diaz A, et al. The proteomic skin profile of moderate-to-severe atopic dermatitis patients shows an inflammatory signature. J Am Acad Dermatol 2020; 82: 690-9.

25. Leach MW, Rottman JB, Hock MB, et al. Immunogenicity/hypersensitivity of biologics. Toxicol Pathol 2014; 42: 293-300.

26. Strand V, Balsa A, Al-Saleh J, et al. Immunogenicity of biologics in chronic inflammatory diseases: a systematic review. BioDrugs 2017; 31: 299-316.

27. Colombel JF. Herpes zoster in patients receiving JAK inhibitors for ulcerative colitis: mechanism, epidemiology, management, and prevention. Inflamm Bowel Dis 2018; 24: 2173-82. 